\title{
Trabalho em equipe: um desafio para a consolidação da estratégia de saúde da família
}

Teamwork: a challenge for family health strategy consolidation

Marize Barros de Souza Araújo ${ }^{1}$

Paulo de Medeiros Rocha ${ }^{2}$

\footnotetext{
${ }^{1}$ Secretaria Municipal de Saúde do Natal/RN. Rua Industrial João M otta 1541/ d 102, Capim Macio. 59082-410 Natal RN. marizern@bol.com.br 2 Departamento de Saúde Coletiva, Universidade Federal do Rio Grande do Norte.
}

\begin{abstract}
Teamwork is one of the main pillars of Family $\mathrm{H}$ ealth Care projects, although it is not a strategy exclusively applied to such programs. It is not frequently discussed in current collective health research studies, but the perspective resulting from the full range of its action favors interdisciplinary and transdisciplinary actions. Thus, when building a Family Health Project, teamwork should be guided by a common health care purpose and the players involved should develop an interaction movement within the team itself as well as in relation to the community. It is there fore critical to establish communication practices for mutual understanding. This paper presents some preliminary considerations on theteamwork strategy in Family $\mathrm{H}$ ealth Careactions, indicating barriers and potentials in the construction of this health care model.
\end{abstract}

Key words Teamwork, Family health, H ealth care mode
Resumo 0 trabalho em equipe, embora não seja uma exclusividade da Saúde da Família, repre senta um de seus principais pilares, ainda pouco discutido em pesqui sas na saúde coletiva. A perspectiva da integralidade das ações favorece uma ação inter/transdisciplinar. Na construção do projeto de Saúde da Família, é necessário que o trabalho em equipeseja norteado por um projeto assistencial comum e que os agentes desenvolvam uma ação de interação entre si e com a comunidade. Para tanto, é imprescindível o desenvolvimento de uma prática comunicativa orientada para o entendimento mútuo. Esse artigo apresenta considerações preliminares sobreo trabal ho em equipe na Estratégia de Saúde da Família sinalizando seus entraves e possibilidades na construção desse modelo assistencial.

Palavras-chave Trabalho em equipe, Saúde da família, M odelo assistencial 
Introdução

A importância do trabalho em equipe na ESF (Estratégia Saúde da Família) é ressaltada, principalmente, pelo aspecto de integralidade nos cuidados de saúde. Considerado um dos princípios doutrinários do Sistema Único de Saúde (SUS), a integralidadereveste-se, no decorrer dos anos 90, e principalmente nesse início de século, deuma importância estratégicaímpar paraa consolidação de um novo modelo de atenção à saúde no Brasil. Para al guns autores, entre eles M attos ${ }^{1} ;$ M attos $^{2}$ e Cecílio ${ }^{3}$, deve ser pensada como uma imagem-objetivo, portanto polissêmica, com variados sentidos. Essencialmente, trabalhamos com a concepção de integralidade como uma dimensão/valor das práticas desaúde. Além decontribuir nessa organização, a integralidade busca uma apreensão ampliada das necessidades desaúde da população atendida. Portanto, pode ser entendida como um "tipo de marcador contínuo" que pode incluir os aspectos objetivos e subjetivos resultantes da interação/relação dos atores em suas práticas no cotidiano das instituições ${ }^{4}$.

Devemos nos lembrar que, durante toda a década pós Constituição Brasileira de 1988, a marca registrada desse período foi a tensão entre o SUS e o modelo neoliberal na área da saúde representado entre outros aspectos pela redução de gastos públicos, políticas sel etivas/focalizadas, incentivos às atividades privadas/mercado. 0 projeto reformador da saúde, consolidado na Reforma Sanitária brasileira, deparou-se assim, no início dos 90, com o forte conflito entre os desejos de mudanças oriundos de sua proposta original e a dura realidade política-econômica-social do período, o queresultou em maiores dificuldades para a implementação do sistema (eseus princípios), conforme Rocha5.

O Programa Saúde da Família (PSF) écriado em 1994, tendo como antecessor o PACS (Programa deAgentes Comunitáriosem Saúde), enos seus primeiros anos de existênciafoi marcado por inquietações e críticas à sua proposta, conforme aponta Paim ${ }^{6}$. Posteriormente, num sucessivo acréscimo de novas proposições, normatizações, modalidades deincentivo (financiamento) econsolidação de práticas inovadoras e exitosas em vários municípios brasileiros, passou a ser considerado como estratégia de reestruturação do sistema de saúde, a partir da Atenção Básica. Tem como pressupostos a implementação dos princípios do SUS (entre o quais a integralidade, que nos interessa mais de perto no presenteartigo), e portanto caráter substitutivo ao buscar um novo modelo deatenção, baseado na promoção da saúde. Tem como elementos centrais o trabalho com adscrição de clientela, 0 acolhimento como porta de entrada para as Unidades de Saúde da Família, a visita domiciliar, a integralidade das práticas e a equipe multiprofissional ${ }^{7}$.

0 trabalho em equipe tem como objetivo a obtenção de impactos sobre os diferentes fatores que interferem no processo saúde doença. A ação interdisci plinar pressupõea possibilidade da prática de um profissional se reconstruir na prática do outro, ambos sendo transformados para a intervenção na realidade em que estão inseridos.

Assim, a abordagem integral dos indivíduos/ famílias é facilitada pela soma de olhares dos distintos profissionais que compõem as equipes interdisciplinares. Dessa maneira, pode-se obter um maior impacto sobre os diferentes fatores que interferem no processo saúde-doença. É semprebom lembrar que a estruturação do trabalho em equipes multiprofissionias no PSF (Programa de Saúde da Família), por si só, não garante uma ruptura com a dinâmica médico-centrada; para tanto, há necessidade de dispositivos que alterem a dinâmica do trabalho em saúde, nos fazeres do cotidiano de cada profissional ${ }^{8}$. Há que se identificar, nessas equipes, os el ementos que configurariam uma nova lógica no agir desses profissionaise na forma como se produz o cuidado em saúde.

Nesse sentido, o perfil dos recursos humanos em saúde deve alterar-se. Uma das maiores dificuldades na implementação da ESF diz respeito à carência de profissionais para atender a esta nova realidade 9 . Faz-se necessário, portanto, o desenvolvimento de um processo de formação e capacitação permanente de todos os profissionais envolvidos ${ }^{10}$.

Essencialmente, 0 entendimento deque o trabalho em equipe constitui a base dessa proposta de mudança nos conduziu ao presente trabal ho. Para que a Estratégia de Saúde da Família desencadeie um processo de construção de novas práticas, considera-se imprescindível que os trabaIhadores, envolvidos nessa estratégia, articulem uma nova dimensão no desenvolvimento do trabalho em equipe. Faz-se necessária a incorporação não apenas de novos conhecimentos, mas mudança na cultura e no compromisso com a gestão pública, que garanta uma prática pautada nos princípios da promoção da saúde.

Pelo fato do PSF surgir no cenário da saúde brasileira somente em meados dos anos 90, há uma nítida escassez de produções científicas sobre equipe de saúde a ele vinculado. N esse sentido, deve-se salientar a distinção de análises entre 
equipes de saúde pré e pós-PSF, ou seja, ele élinha demarcatória decisiva (antes e depois) para as análises sobre o trabalho em equipe na saúde brasileira.

M esmo entendendo queuma gama importante dessas referências teóricas refere se ao período pré-PSF, resolvemos utilizá-las como elementos importantes de reflexão por conterem subsídios valiosos para a atual situação de saúde. Portanto, ainda que tratem de situações distintas das equipes de PSF, possibilitaram uma base analítica teórica que permite, por analogias, avançar na presente transição de modelos assistenciais de saúde. Exemplo: destaca-se desses estudos a tese de doutorado de Peduzzi ${ }^{11}$, que será bastante referida neste trabalho.

0 presente artigo parte desses pressupostose desafios trazidos pelas novas formas de organização do trabalho das equipes em saúde que atuam no PSF, em especial as análises realizadas em pesquisa desenvolvida em Natal/RN, em $2003^{12}$.

Equipe de saúde no PSF: caminhos e possibilidades

No início dos anos 90, as discussões sobre mudança de práticas na saúde estavam muito mais voltadas para o nível do aparato legal e da estrutura político-administrativa do SUS, como elementos de maior destaque na conjuntura política. Essa é apenas uma constatação do elenco de prioridades político-institucionais quealimentavam o movimento reformador eo debate da ocasião, sem negar todo o acúmulo e a importância das discussões sobre aparelho formador e o SUS, perfil do novo profissional para o sistema, integração docente-assistencial, etc., entre outras contribuições.

É inegável, porém, que não havia uma preocupação maior com relação aos atores que concretamenteoperariam essas mudanças. N esse sentido, um dos fatos críticos de maior destaque no Brasil dos últimos 20 anos era justamente a sempre adiada conferência nacional específica dos recursos humanos da área.

H avia uma nítida separação entre os profissionais e os pacientes, entre as equipes e as comunidades, entre os agentes e os seus meios de trabalho, sendo tal situação reproduzida tanto no setor público como no privado. Assim, estruturar serviços com base nas equipes de saúde contribui para a quebra da divisão do processo de trabal ho, para a responsabilização pelos problemas apresentados e para a superação da inércia e indiferença burocrática dos serviços públicos de saúde ${ }^{13}$.

Sobre a forma de organização dos processos de trabal ho no interior de cada unidade de saúde, predominava a hegemonia do poder técnico e político dos profissionais médicos, havia conflito com outros profissionais de nível universitário, as categorias denível médio eram maisnumerosas, embora menos qualificadas e mais desvalorizadas em termos salariais ${ }^{14}$. Em geral, 0 trabal ho éfeito deforma fragmentada eainda não se correlaciona a finalidade deseu trabal ho específico com o objetivo do trabal ho em saúde. M ou$\mathrm{ra}^{14}$ salienta que "falar em mudanças nas práticas desaúdevisando à redefinição do modelo deatenção, implica em abordar a forma ou o modo como essas práticas são produzidas e traduzidas em ações de saúde" ${ }^{14}$.

Sobre o quadro mais amplo das contradições e indefinições sobre o trabalho dos profissionais de saúde na época não só a sociedade mostravase indiferente à situação crítica do setor saúde, mas, também, os profissionais que muitas vezes adotavam posturas alienadas ${ }^{15}$.

Vejamos agora um conjunto de principais definições governamentais (através do Ministé rio da Saúde) sobre as mudanças preconizadas pelo PSF, iniciadas em meados dos anos 90 , eque são fundamentais para a compreensão do nosso objeto - o trabal ho em equipe nesse novo modelo de aten ção que vem sendo implementado na atualidade da saúde brasileira. Em seguida, apresentaremos, numa ordem cronológica dos trabaIhos, algumas revisões/autores cujas contribuições nos últimos anos têm sido de extrema relevância para o debate temático do trabalho em equipe de saúde.

A partir de 1996, com a edição da N OB/9616, cristaliza-se a necessidade de redefinição do modelo de saúde, adotando como estratégia principal a ampliação de cobertura do PSF/PACS. Assim, para uma nova estratégia, faz-se necessário um novo profissional. Se a formação dos profissionais não for transformada no aparelho formador, o modelo de atenção também não o será na realidade do dia-a-dia ${ }^{17}$.

Segundo orientações do Ministério da Saú$\mathrm{de}^{7}$, no PSF as ações são estruturadas no trabalho em equipe e buscam humanizar as práticas de saúde, com o objetivo de obter a satisfação do usuário através do estreito relacionamento dos profissionais com a comunidade. 0 processo de trabal ho das equipes se estrutura a partir do conceito de delimitação do território, mapeamento das áreas e microáreas (a primeira entendida 
como um conjunto de microáreas contíguas sob a responsabilidade de uma equipe, onde residem em torno de 2.500 a 4.500 pessoas e a segunda representa a área de atuação de um agente comunitário de saúde, onde moram cerca de 400 a 750 pessoas, cadastramento familiar e utilização do sistema de informação de atenção básica (SIAB).

As principais responsabilidades atualizadas, de acordo com a N OAS/20017' constituem: saúde da criança; saúde da mulher; controle de hipertensão; controle de diabetes melittus; controlede tuberculose; eliminação da hanseníase; ações de saúde bucal. Somam-se a isso visitas domiciliares, reuniões entre os profissionais e a comunidade, atividades educativas com grupos definidos, ações administrativas de supervisão e educação continuada.

Seguindo essas diretrizes, uma equipe desaúde da família deve ser composta minimamente de um médico, um enfermeiro, um auxiliar de enfermagem e quatro ou seis agentes comunitários de saúde. A incorporação de outras categorias profissionais dependerá dosmunicípios. Cada equipe deveser responsável pela cobertura de 600 a 1.000 famílias.

As atividades da equipe seriam: conhecer a realidade das famílias; identificar os problemas de saúde e situação de risco; realizar o planejamento e programação local com a participação comunitária; estabelecer vínculo de confiança com os usuários através de uma conduta ética; resolver os problemas de saúde em nível de atenção básica; garantir o acesso à comunidade dentro de um tratamento de referência e contra-referência; prestar atendimento integral à demanda adscrita, respondendo à demanda de forma contínua e racionalizada; coordenar e/ou participar de grupos de educação em saúde; promover ações intersetoriais e outras parcerias com organizações formais e informais existentes na comunidade para o enfrentamento conjunto dos problemas identificados; fomentar a participação popular, discutindo com a comunidade conceitos de cidadania, de direito à saúde e suas bases legais; incentivar a participação ativa da comunidade nos consel hos locais de saúde, no conseIho municipal de saúde e auxiliar na implantação do cartão nacional de saúde.

A implantação do PSF por si só não garante a modificação do modelo assistencial médicocentrado. Esta depende da mudança na forma de se produzir o cuidado, assim como dos diversos modos de agir dos profissionais entre si e com os usuários. O "campo do cuidado" e a in- teração abrem a possibilidade de cada um usar todo o seu potencial criativo e criador na relação com o usuário, para juntos realizarem a produção do cuidado ${ }^{15}$.

Sobre o processo de trabalho, Merhy ${ }^{18}$ afirma: As especificidades do trabalho em saúde demarcam um campo específico das práticas, sendo que estas se desenvolvem em um espaço de encontro ede intervenção denominado de espaço intercessor, enquanto espaço onde se processa a produção de ações de saúde e onde cada trabalhador potencialmente pode decidir coisas, ou seja, exerce um certo autogoverno.

A operação cotidiana desse autogoverno, do estabelecimento de espaços intercessores na produção de atos de saúde se dá através do "trabal ho vivo em ato" aquele que ocorre no momento mesmo em que ele se realiza, no imediato fazer da produção do serviço. A mudança assistencial dar-se-ia a partir da reorganização do processo de trabalho estruturado na ação multiprofissional. M erhy ${ }^{18}$ menciona ainda que esses novos fazeres e práticas se materializam em tecnologias detrabal ho usadas para produzir a saúde, que são traduzidas a partir dos conhecimentos e agires aplicados à produção de algo eque se classificam em duras e leve-duras, ou lugares do "trabal ho morto". Por outro lado, os conhecimentos podem estar diluídos nas experiências e modos singulares de cada profissional operar o seu "trabalho vivo" que está inscrito no campo das tecnologias leves, fundamentais ao trabalho em saúde ${ }^{18}$. 0 aprisionamento de cada um em seu campo específico de saberes e práticas limita o processo de trabalho às estruturas rígidas do conhecimento técno-estruturado, tornando-o trabal ho "mortodependente". Para que o trabalho em equipe seja viabilizado, há necessidade de uma relação interativa entre os trabal hadores, mediada pela troca de conhecimentos e articulação de um "campo de produção do cuidado" comum a todos ${ }^{19}$.

0 trabalho em equipe é uma modalidade do trabal ho coletivo, sendo caracterizado pela relação recíproca entre as dimensões complementares de trabalho e interação $0^{11}$. Nesse estudo, observa-se que, apesar das escassas definições sobre equipe de saúde, na literatura foram encontradas diferentes abordagens sobre esse tema, onde se destacam: os resultados, as relações e a interdisciplinaridade. Na lógica dos resultados, a equipeé concebida como um recurso para o aumento da produtividade e da racionalização dos serviços. Nas relações, as pesquisas utilizam como referência os conceitos da psicologia analisando as equipes com base nas relações interpessoais, 
assim como nos processos psíquicos. Na perspectiva da interdisciplinaridade, situam-se os trabaIhos que trazem à discussão a articulação de saberes e a divisão do trabalho, ou seja, da especialização do trabalho em saúde.

Quanto as diversidades sobreà concepção dos agentes (profissionais de saúde) acerca do trabaIho em equipe, observa-se que, para os médicos, a equipe évista como sendo equipe médica. $\mathrm{Ou}$ tros trabalhadores de nível superior defendem a construção de uma equipe multiprofissional e referem ainda a dificuldade em constituí-la por sentirem falta de espaço dos "não-médicos" para exercício de suas funções. Quanto aos de nível médio, demonstraram pouca preocupação com essa situação, uma vez que se consideram bem definidos nas suas funções, apontam apenas a dificuldade das relações de subordinação com as chefias imediatas ${ }^{11}$.

Assim, diante da diversidade das concepções detrabalho em equipe, a idéia de equipe perpassa duas concepções distintas: a equipecomo agrupamento de agentes e a equipe como integração entre relações e práticas. A primeira é caracterizada pela fragmentação das ações e a segunda, pela construção de possibilidades de recomposição. Estaúltima estaria consoante com a proposta da integral idade das ações de saúdee a necessidade contemporânea de recomposição dos saberes e trabalhos especializados.

Dessa forma, o conceito e tipologia para a equipe de saúde se refere a duas modalidades: equipe agrupamento, em que há justaposição de ações e agrupamento dos agentes, e equipe integração, que desenvolve a articulação das ações e interação dos agentes. Em ambas, estão presentes as diversas técnicas dos trabalhos especializados e a desigualdade de valor atribuída a esses diferentes trabalhos ${ }^{11}$.

Nesse sentido, tomaremos como referência teórica para efeitos deste artigo o conceito "equipe integração", mesmo tendo sido desenvolvido em uma situação diferente do contexto de nosso trabalho. Entretanto, o adotaremos por reunir alguns elementos (ação comunicativa e integração das práticas) que consideramos essenciais para o trabalho no PSF.

Um elemento de forte consenso entre os autores está no fato de que o trabalho em equipe implica o compartilhar do planejamento, a divisão de tarefas, a cooperação e a colaboração. A interação democrática entre diferentes atores, saberes, práticas, interesses enecessidades representam a possibilidade do novo no trabalho em equipe ${ }^{20}$.
A dificuldade do trabal ho em equipe está relacionada com as diferentes concepções so bre o conceito de equipe. Dentre essas, se observam as definições: a equipe como um conjunto ou grupo de pessoas que desempenham uma tarefa ou trabalho não importando, nesse caso, os objetivos e as relações interpessoais; ou a equipe como um grupo de pessoas que tem um objetivo comum. Sendo, nesse caso, fundamental que tenham o mesmo objetivo, não importando como cada um pretenda alcançá-lo; ou a equipe como um conjunto de pessoas que além de um objetivo comum pretendem alcançá-lo de forma compartilhada; ou referese ainda à equipe como um conjunto ou grupo de pessoas cujo objetivo é resultante da negociação/discussão entre todos os membros do grupo e por fim com o conceito que considera equipe como um grupo de pessoas com habilidades complementares, comprometidas umas com as outras e pelo objetivo comum, obtido através da negociação entre os atores sociais envolvidos no plano de trabalho ${ }^{21}$

No processo de produção em saúde, a denominação "equipe" sempre fará referência a uma situação de trabal ho, e este, referindo-seà obtenção de bens ou produtos para a atenção às necessidades humanas. Além disso, destacam as habilidades relacionais tomadas como ferramentas essenciais da proposta e transformação de modelos assistenciai ${ }^{22}$.

Na proposta de Saúde da Família, o trabalho em equipe constitui uma prática em que a comunicação entre os profissionais deve fazer parte do exercício cotidiano do trabal ho, no qual os agentes operam a articulação das intervenções técnicas por meio da linguagem.

$\mathrm{Na}$ equipe multiprofissional, essa articulação refere-se à recomposição de processos de trabaIhos distintos e, portanto, deve considerar as conexões e interfaces existentes entre as intervenções peculiares de cada área profissional, preservando as respectivas especificidades. Peduzzi ${ }^{11}$ chama atenção ainda para o fato de a formação dos profissionais de saúde estar pautada no modelo biomédico, o que pode representar uma limitação para a atuação na esfera da interação, entendida como uma prática comunicativa por meio da qual os envolvidos buscam o consenso quanto a um projeto comum ${ }^{31}$.

0 estabelecimento de uma relação dialógica no interior das unidades de saúde pode contribuir para a superação de relações hierarquizadas, em que os profissionais raramente conhecem as potencialidades dos outros, reproduzindo, dessa 
forma, a divisão social do trabal ho eestabelecendo relações de mando e autoridade ${ }^{23}$.

Nesse sentido, concordamos com Paim et al. ${ }^{24}$ ao afirmarem que um profissional de saúde, eem especial de saúde pública, necessita das seguintes características: Capacidade de análise do contexto em relação às práticas que realiza; compreensão da organização e gestão do processo detrabalho em saúde; exercício de um agir comunicativo ao lado do pensamento estratégico; advocacy ou habilidade para proceder denúncia de situações e convencimento de inter locutores; tolerância e diálogo em situações de conflitos; atenção a problemas e necessidades de saúde; senso crítico quanto à efetividade e ética das intervenções propostas ou realizadas e finalmente permanente questionamento sobre o significado eo sentido do trabalho e dos projetos de vida.

Assim, são importantes as considerações de Leite $^{25}$ ao demonstrar que tecnologias importantes na qualificação da assistência como a interação, o trabalho em equipe, o planejamento situacional e a comunicação são pouco valorizadas pelos diferentes níveis gerenciais. Os novos modelos de organização da assistência buscam estimular a construção de equipes, ao permitirem a recomposição dos meios de trabal ho, a reestruturação das atividades dos agentes e a redefinição das relações sociais e técnicas sob as quais se realizam os trabalhos.

A concepção de trabal ho em equipe está vinculada à de processo de trabalho e vem, portanto, sofrendo transformações ao longo do tempo. $\mathrm{H}$ istoricamente, surge da necessidade do homem de somar esforços para alcançar objetivos de forma mais fácil e de atender às exigências do processo de produção moderno.

0 trabalho em equipe é uma forma eficiente de estruturação, organização e de aproveitamento das habilidades humanas. Possibilita uma visão mais global e coletiva do trabalho, reforça 0 compartilhamento de tarefas e a necessidade de cooperação para alcançar objetivos comuns ${ }^{25}$. Se não houver interação entre os profissionais das equipes de Saúde da Família, corre-se o risco de repetir a prática fragmentada, desumana e centrada no enfoque biológico individual com diferente valoração social dos diversos trabal hos ${ }^{10}$.

\section{Algumas reflexões \\ e suas conexões com o trabal ho em equipe}

A Saúde da Família requer a construção de um projeto assistencial comum com complementa- ridade dos trabalhos especializados, em que os agentes envolvidos estabeleçam interação entre si ecom os usuários. 0 trabalho em equipe pressupõe, portanto, uma relação recíproca de comunicação einteração. A comunicação em busca de consenso entreos profissionais traduz-seem qualidadena aten ção integral às necessi dades de saúde da clientela.

Duas grandes reflexões foram estimuladas a partir dessa revisão teórica sobre equipe de saúde (multiprofissional e PSF). A primeira diz respeito ao tema da inter/transdiciplinaridade ea segunda sobre a interação na perspectiva habermasiana (ação comunicativa). Ambas tornaram-se indispensáveis em face do objeto pesquisado - trabaIho em equipe do PSF - e pela adoção dos conceitos básicos etipologia de equipeutilizados na fundamentação teórica do trabalho, conforme apresentado em Araújo ${ }^{12}$. Esses dois textos a seguir possuem, assim, uma forte conexão entre si, no sentido de oferecem elementos teóricos inovadores para uma compreensão integral do processo de trabalho em equipe que vem sendo realizado nas práticas do PSF. Articulam-setambém com as considerações finais do presente artigo.

Interdisciplinaridade e

transdisciplinaridade:

um campo em construção no PSF

Diante da situação decriseno setor saúdeno Brasil, ao longo dos anos têm sido propostos novos modelos assistenciais com uma forte tendência de organizar as práticas de saúde no trabalho interdisciplinar, com o objetivo de atender em quantidade e qualidade e de forma equânime as demandas da população.

A interdisciplinaridade se evidencia desde a antiga Grécia, onde o ideal da educação era o saber da totalidade. A formação integral (Paidéa) envolvia o ensino da gramática, dialética, retórica, aritmética, geometria, música e astronomia ${ }^{26}$.

A partir do século XIX, conforme Minayo apud Gomes et al. ${ }^{27}$, observa-seum processo crescente da disciplinarização, oriundo da hegemonia do paradigma do positivismo, que tinha na ciência a expressão máxima da racionalidadehumana. Assi m, as disciplinas começam a se firmar de forma isolada, resultando numa excessiva especialização e fragmentação do saber ${ }^{27}$. A interdisciplinaridade não representa a anulação da disciplinaridade, nem a especificidade de cada saber, mas a possibilidade de uma compreensão integral do ser humano e do processo saúde-do- 
ença, objeto do trabalho em saúde, passa necessariamente por uma abordagem interdisciplinar e por uma prática multiprofissional ${ }^{20}$.

A construção da interdisciplinaridade tem sido um processo contínuo e crescente no setor saúde, dada a necessidade de superação da fragmentação do conhecimento humano, na busca de uma visão globalizada que dê conta da complexa dimensão do processo saúde-doença.

O conceito de saúde como qualidade de vida requer a passagem de um trabalho individual, compartimentado para uma ação coletiva. Supõe a compreensão de pensamentos e ações desiguais e pressupõe a existência de pontos comuns entre pessoas que pretendem desempenhar uma ação interdisciplinar ${ }^{26}$.

A interdisciplinaridade representa uma possibilidade de aproximação ou estreitamento entre as partes, uma vez que a totalidade nunca pode ser atingida. Faz-se necessária, portanto, a adoção de uma visão dialética dos obstáculos de sua construção ${ }^{28}$.

Em análise epistemológica, Leite ${ }^{28}$ afirma que "disciplina" tem o mesmo sentido que ciência, instrução, ensino. 0 prefixo "inter" está relacionado com troca, reciprocidade. Assim, interdisciplinar refere-se à troca entre áreas de conhecimento. Para atingir esses objetivos, deve-seestabelecer entre os membros da equipeuma nova concepção de trabalho que admita a diversidade de ação, busque constantemente o consenso e que esteja baseada na interdisciplinaridade. 0 trabalho interdisciplinar tem como significado: a possibilidade de a prática de um profissional sereconstruir na prática do outro, transformando ambas na intervenção do contexto onde estão inseridas?.

Para efeito de enriquecer o debate, destacamsealgumasformas de relações interdisciplinares ${ }^{29}$ :

Multidisciplinaridade: refere-se basicamente à associação ou justaposição de disciplinas que abordam um mesmo objeto a partir de distintos pontos de vista. Não se verifica uma integração interdisciplinar.

Interdisciplinaridade auxiliar: interação de diferentes disciplinas científicas, sob a dominação de uma delas, que se impõe às outras como campo integrador e coordenador.

M etadisciplinaridade: representa uma contribuição ao esquema de Jantsch. A interação e inter-relações das disciplinas são asseguradas por uma metadisciplina situada num nível epistemológico superior; esta não se impõe como coordenadora, mas como integradora do campo metadisciplinar [...].
Interdisciplinaridade: busca-se a superação das fronteiras disciplinares [...] estabelecimento de uma linguagem interdisciplinar consensualmente construída entre os cientistas. O bserva-se troca entre as disciplinas com integração de instrumentos, métodos e esquemas conceituais.

Transdisciplinaridade: indica uma integração das disciplinas de um campo particular parauma premissa geral compartilhada; estruturadas em sistemas de vários níveis e com objetivos diversificados [...] há ten dência de horizontalização das relações interdisciplinares ${ }^{29}$.

Essa classificação possui um caráter didático, não éobjetivo desteartigo discuti-la extensamente; entretanto, denuncia a necessidade de ampliação do diálogo interdisciplinar.

Almeida Filho ${ }^{29}$ comenta que a transdisciplinaridade tem como definição: “a possibilidade de comunicação não entre os campos disciplinares, mas, entreagentes em cada campo, através da circulação não dos discursos, mas dos sujeitos dos discursos". Diferentemente dos especialistas, restritos ao seu campo disciplinar, os agentes com uma formação transdisciplinar podem transitar por pelo menos dois campos disciplinares.

Nesse sentido, no campo da saúde coletiva, a complexidade de seu objeto exigiria uma formação transdisciplinar, dado às múltiplas determinações do processo saúde-doença-cuidado.

A ampliação do conceito de saúde a partir da 8a Conferência Nacional de Saúde (1986), que adota um caráter pluridimensional, dá inicio a uma série de tentativas de buscar a construção de relações interdisciplinares, como exemplos à integração de fatores biopsicossociais, a medicina integral, assim como a medicina social ${ }^{30}$.

\section{A interação habermasiana: construindo um novo caminho}

$\mathrm{Na}$ perspectiva de Habermas ${ }^{31}$, a interação éuma prática comunicativa da qual participam pelo menos dois sujeitos, que através da linguagem buscam compreensão e consenso mútuo em torno de um projeto comum. N esse agir comunicativo, os atores sofrem influência, simultaneamente, de al go no mundo objetivo, no mundo social ou normativo e no mundo subjetivo. Esse conceito tríplice de mundo foi construído a partir das proposições popperianas, para as quais 0 mundo objetivo está relacionado ao mundo físico ou ao estado das coisas existentes; o mundo social ou normativo refere-se às normas sociaise culturais e o mundo subjetivo é o mundo inter- 
no de cada sujeito ao qual este tem acesso privilegiado ${ }^{32}$.

Entretanto, énecessário distinguir o agir comunicativo (agir para o entendimento mútuo) do agir para o sucesso (agir estratégico). Segundo $\mathrm{H}_{\text {abermas }}{ }^{31}$ : Q uando os atores estão orientados para o sucesso, el es buscam alcançar os obj etivos de sua ação influindo externamente, por meio de armas ou bens, ameaças ou seduções, sobre a definição da situação ou sobre as decisões ou motivos de seus adversários, nessa perspectiva a coordenação das ações dos sujeitos depende da maneira como se entrosam os interesses de ganho egocêntricos. [...]. No agir comunicativo, os atores harmonizam internamente seus planos de ação e perseguem suas respectivas metas sob a condição deum acordo existente ou a se negociar sobre a situação ou sobre a situação e as conseqüências esperadas".

A ação comunicativa mediada pela linguagem produz um movimento através do qual o sujeito quefala, ao comunicar-secom um outro que ouve, expressa aquilo que está pensando. 0 acordo não pode ser imposto a outra parte, não pode ser extorquido ao adversário por meio demani pulações. 0 queadvém de manifestações externas não pode ser tido como acordo. Quando o sujeito profere verbalmente al go dentro de um contexto cotidiano, ele está se referindo a coisas inter-relacionadas nos três mundos; assim, a linguagem preenche a tríplice função de: reprodução da cultura ou preservações detradições; integração social ou coordenação dos planos de diferentes atores na integração social - é nessa função da linguagem que se dá o desenvolvimento da teoria do agir comunicativo e a função de socialização da interpretação cultural das necessidades ${ }^{31}$.

Dessa forma, a interação refere-se a uma ação comunicativa, quando osatores harmonizam seus planos de ação e são guiados por normas de vigência obrigatória, ou por meio da negociação sobre a situação ou conseqüências esperadas. Através da capacidade de agir em vista de um objetivo ou do interesse da execução de planos de ação, os sujeitos buscam acordos para entendimento mútuo: nesse processo, estão excluídas a imposição, a coerção e a extorsão.

Numa atitude orientada para 0 entendimento mútuo, o falante utiliza no seu proferimento inteligível as seguintes pretensões de validez: a verdade no enunciado, 0 ato da fala é correto relativamente ao contexto normativo existente e a intenção é coerente com o modo como é proferida. Quando uma dessas expectativas de validade é questionada por um dos participantes, a prática comunicativa é suspensa e inaugura-se uma nova forma de comunicação: o discurso, que teria a função de fundamentar as pretensões de validade das afirmações e das normas nas quais se baseia o agir comunicativo. 0 discurso para Habermas serve para levantar ou inventariar as necessidades e os interesses das pessoas atingidas por uma decisão a ser tomada. E no discurso estas necessidades são discutidas e avaliadas ${ }^{32}$.

Entretanto, não équal quer discurso que pode servir para estabelecer normas justas. Considerando que existem muitas possibilidades de influir na opinião dos outros, discurso em queuns são obrigados a aceitar as opiniões dos outros não é apto para isso. A única maneira justa de influir na opinião dos outroséo recurso de bons argumento ${ }^{32}$.

Somentea ação comunicativa pressupõeo uso da linguagem em todas as suas dimensões, estando referida ao mesmo tempo aos três mundos, articulados pelo mundo da vida ${ }^{33}$. Nessa perspectiva, "a aproximação ao mundo deixa de ter a marca da dominação ou o controle do sujeito sobre um objeto e passa a representar uma construção solidária, na qual os atores se entendem sobre a melhor forma de atuar" ${ }^{\prime 3}$.

$\mathrm{N}$ as relações orientadas para 0 entendimento mútuo, o ser humano é visto como pessoa capaz de estabelecer relações e cujo modo de agir está orientado para a comunicação, interação e participação, tendo como principal motivação a solidariedade e o sentido comunitário.

No discurso, realiza-seum diálogo empenhado na argumentação racional convincente, que visa $o$ entendimento isento dequalquer forma de violência interna ou externa. A comunicação pode ser restabelecida, se pretensões de validez, postas em questão, forem reafirmadas erevalidadas discursivamente ${ }^{11}$.

Portanto, a teoria da ação comunicativa representa a possibilidade de construção de um novo e democrático agir nas práticas de saúde, buscando uma compreensão do mundo no qual a teoria e a prática estariam interligadas, através de ações concretas numa dinâmica de interação entre os atores envolvidos.

\section{Considerações finais}

0 trabal ho em equipe no contexto do PSF ganha uma nova dimensão no sentido da divisão deresponsabilidades do cuidado entre os membros da equipe, na qual todos participam com suas especificidades contribuindo para a qualidade da prestação das ações de saúde. A concepção integral do cuidado favorece a ação interdisciplinar nas 
práticas, onde a valorização das diversas disciplinas contribui para uma abordagem ampla e resolutiva do cuidado. Nessa perspectiva, a responsabilidade da atenção passa a ser descentralizada da figura do profissional médico, considerado o centro da equipe no modelo hospitalocêntrico, sendo dividida entre os membros da equipe.

A importância do diálogo na busca do consenso constitui elemento imprescindível para o bom desenvolvimento do trabal ho em equipe. Isso aponta à possibilidade do desenvolvimento de uma prática comunicativa. 0 trabalho em equipe "provoca" a escuta do outro. 0 que pressupõe 0 estabelecimento de um canal de comunicação.

0 processo de trabalho em saúde está fundamentado numa inter-relação pessoal forte onde os conflitos também estão presentes no dia-a-dia da equipe ${ }^{34}$. Deve-se considerar ainda que uma equipe é composta por pessoas que trazem especificidades próprias como: gênero, inserção social, tempo e vínculo de trabalho, experiências profissionais e de vida, formação e capacitação, visão de mundo, diferenças salariais e, por fim, interesses próprios. Essas diferenças exercem influência sobre esse processo detrabal ho, uma vez que estão presentes no agir de cada profissional, mas não inviabilizam o exercício da equipe. A mudança nas relações de trabalho não acontecerá de maneira rápida, os profissionais que compõem as equipes vêm deuma prática na qual predomina o poder do nível superior sobre o nível médio, da categoria médica sobreas demais. Nesse contexto, relações de poder hierarquizadas, estabelecidas entre os profissionais, configuram elementos que fortalecem a situação de status de algumas profissões sobre outras, garantindo posições de liderança na equipe. Dessa forma, se faz necessário redefinir no cotidiano das USFs responsabilidades e competências dos integrantes da equipe de saúde, sem esquecer os pontos de interseção entre as disciplinas.

A forma como as pessoas vivem seus problemas no interior dos serviços implica o estabelecimento de canais de interação. Para o desenvolvimento de ações de saúde na perspectiva da integralidade, faz-se necessária uma aproximação integral entre os sujeitos que prestam o cuidado. Ou seja, estabelecer uma prática comunicativa como estratégia para o enfrentamento dos conflitos significa romper com velhas estruturas hierarquizadas, tão presentes no modelo de saúde hegemônico. Nessa realidade, os profissionais de saúde desenvolvem o trabalho com relativa autonomia, mas com subordinação ao fazer do médico, ao contrário do que acontece na $E S F$, em que as relações de poder se enfraquecem quando se prioriza a escuta. A ação comunicativa é contrária a qualquer tipo de repressão dos direitos à liberdade do sujeito. Torna-se essencial que os profissionais se relacionem em um ambiente livre de coações, para que juntos se comuniquem, estabelecendo interação, possibilitando assim a construção de um novo modelo de saúde.
Colaboradores

M BSAraújo ePM Rocha participaram igualmente de todas as etapas da elaboração do artigo. 


\section{Referências}

1. M attos RA. Os sentidos da integralidade: al gumas reflexões acerca dos valores que merecem ser defendidos. In: Pinheiro R, M attos RA, organizadores. Os sentidos da integralidadena atenção e no cuidado à saúde. Rio de Janeiro: IMS- UERJ/ABRASC 0; 2001. p. 39-64. Integralidade e a formulação de políticas específicas de saúde. In: Pinheiro R, M attos RA, organizadores. Construção da integralidade: cotidiano, saberes e práticas de saúde. Rio de Janeiro: IM S-UERJ/ ABRASC0; 2003. p. 45-59.

3. Cecílio LCO. As necessidades de saúde como conceito estruturante na luta pela integralidade e eqüidade na atenção em saúde. In: Pinheiro R, M attos RA, organizadores. Os sentidos da integralidade na atenção e no cuidado à saúde. Rio de Janeiro: IMS-UERJ/ABRASCO; 2001. p. 113-126.

4. Pinheiro R, Luz MT. Práticas eficazes $x$ modelos ideais: ação e pensamento na construção da integralidade. In: Pinheiro R, Mattos RA, organizadores. Construção da integralidade: cotidiano, saberes e práticas de saúde. Rio de Janeiro: IM S-UERJ/ABRASC0; 2003. p. 7-34.

5. Rocha PM. No limiar do século XXI: gl obalização esaúde, desafios da proteção social no Brasil dos anos 90 [tese]. Rio de Janeiro (RJ): IM S-UERJ; 1997.

6. Paim JS. Saúde da família: espaço de reflexão e de contra-hegemonia. Interface - comunicação, saúde, educação 2001; 9:143-145.

7. Brasil. Ministério da Saúde. Departamento de Atenção Básica. Guia prático do programa de saúde da família. Brasília; 2001.

8. Franco TB, M erhy EE. PSF: contradições e novos desafios. In: Conferência Nacional de Saúde. Tribuna Livre 2000. [acessado $2000 \mathrm{Abr} 28$ ]. Disponível em: http:// www.datasus.gov.br/cns/temas/tribuna.htm

9. Campos FE, Belisário SA. O Programa de Saúde da Família e os desafios para a formação profissional ea educação continuada. Interface - comunicação, saúde, educação 2001; 9:133-141.

10. Almeida M CP, M ishima SM . 0 desafio do trabalho em equipe na atenção à Saúde da Família: construindo "novas autonomias" no trabalho. Interface - comunicação, saúde, educação 2001; 9:150-153.

11. Peduzzi M . Equipe multiprofissional de saúde: a interface entre o trabalho e interação [tese]. Campinas (SP): Faculdade deCiências M édicas, Universidade Estadual de Campinas; 1998.

12. Araújo MB. A Equipe de Saúde no PSF: mudando práticas? Estudo de Caso no município de Natal/RN [dissertação]. Natal (RN): Departamento de Enfermagem da UniversidadeFederal do Rio Grandedo N orte; 2004.

13. Campos GWS. Reforma da Reforma: repensando a saúde. São Paulo: Hucitec; 1992.

14. Moura RM F. O processo de trabalho da equipe multiprofissional em centros de saúde: (vi) vendo eindagando. Anais do Congresso da ABRASCO, 1994; Olinda/PE.

15. Campos GWS. Considerações sobre a arte da ciência da mudança: revolução de coisas e reforma das pessoas. O caso da saúde. In: Cecílio LCO, organizador. Inventando a mudança na saúde. São Paulo: Hucitec; 1994. p.29-87.

16. Brasil. M inistério da Saúde. Norma O peracional Básica - SU S 01/1996. Gestão Plena com Responsabilidade pela Saúde da População. Portaria M S/GM N ․o 2.203/1996.

17. Levcovitz E, Garrido NG. Saúde da família: a procura de um modelo anunciado. Cadernos de Saúde da Família 1996; 1(1): 3-7.
18. M erhy EE. Em busca do tempo perdido: a micropolitica do trabalho vivo em saúde. In: M erhy EE, O nocko $\mathrm{R}$, organizadores. Agir em saúde: um desafio para 0 público. São Paulo: Hucitec; 1997. p.71-112.

19. Franco TB, Merhy EE. PSF: Contradições de um programa destinado a mudanças de um modelo tecno-assistencial. Campinas: UNICAM P; 1998. [M imeo].

20. Feuerweker LCM, Sena RR. Interdisciplinaridade, trabalho multiprofissional eem equipe. Sinônimos? Como se relacionam eo quetêm a ver com nossa vida? Revista Olho M ágico 1999; 5:18.

21. Piancastelli CH, Faria HP, Silveira MR. O trabalho em equipe. In: SantanaJP, organizador. O rganização do cuidado a partir de problemas: uma alternativa metodológica para a atuação da equipe de saúde da família. Brasília: OPAS/Representação do Brasil; 2000. p 45-50.

22. Ciampone MHT, Peduzzi M. Trabalho em equipe e trabalho em grupo no Programa de Saúde da Família. Revista Brasileira de Enfermagem 2000; 53: 43-147.

23. Mishima SM, et al. 0 velho trabalho em equipe pode ganhar cara nova? U ma perspectiva do trabaIho gerencial. Saúde em Debate 2000; 54:66-74.

24. Paim JS, Almeida Filho N. A crise na saúde pública e utopia da saúde coletiva. Salvador: Casa da Qualidade Editora; 2000.

25. M otta RP. Desempenho em equipes de saúde: Manual. Rio de Janeiro: Editora FGV; 2001.

26. Westphal MF, M endes R. Cidade saudável: uma expe riência de interdisciplinaridade e intersetorialidade. Revista de Administração Pública 2000; 34(b):47-61.

27. Gomes R, D eslandes SF. Interdisciplinaridade na saúde pública: um campo em construção. Revista LatinoAmericana de Enfermagem 1994; 2 (2):103-114.

28. Leite JCA. 0 trabalho da enfermeira na equipe de saúde da família: em busca da interdisciplinaridade [dissertação]. Belo Horizonte (M G): Escola de Enfermagem/UFM G; 2001.

29. Almeida Filho N. Intersetorialidade, transdisciplinaridade e saúde coletiva: atualizando um debate em aberto. Revista deAdministração Pública 2000; 34(b):11-34.

30. Nunes ED. Interdisciplinaridade: conjugar saberes Saúde em D ebate 2002; 26(62):249-258.

31. Habermas J. Consciência moral eagir comunicativo. Rio de Janeiro: Tempo Brasileiro; 1989.

32. Kesselring $\mathrm{T}$. De onde provêm as normas éticas? $\mathrm{Da}$ decisão individual ou do discurso livre? A controvérsia entre $\mathrm{H}$ abermas e Tugendhat. In: De Boni LA, organizador. Finitude e transcendência. Petrópolis: Vozes; 1996. p. 766-781.

33. Artmann E. Interdisciplinaridade no enfoqueintersubjetivo habermasiano; reflexões sobre planejamento e AIDS. Rev C S Col 2001; 1:183-195.

34. Nogueira RP. 0 trabalho nos serviços de saúde. In: Santana JP, organizador. Organização do cuidado a partir de problemas: uma alternativa metodológica para a atuação da equipe desaúdeda família. Brasília: OPAS/ Representação do Brasil; 2000. p. 59-63.

Artigo apresentado em janeiro de 2005

Aprovado em 21/09/2006

Versão final apresentada em 07/12/06 